\title{
nature neuroscience
}

\section{Time to reform European science funding}

$\mathbf{L}$ aments about a "brain drain" of Europe's young scientists to the USA abounded at the recent Federation of European Neuroscience Societies (FENS) Forum 2004 in Lisbon. By some reports, a third or more of the young scientists who pursue postdoctoral training in the United States remain in North America, where they find it relatively easy to secure jobs and funding in a scientific market spanning five time zones. In contrast, most European scientists can compete for funding only in their own country, where the available pots may be small. But there is no compelling reason that neuroscience in Europe should remain bound by national borders. Vigorous supranational European funding for basic science could go a long way toward making careers in Europe more attractive to emigrant postdocs.

Part of the problem is mediocre overall funding. Start-up packages for new neuroscience faculty members at US research universities average $\$ 400,000$ or more, but packages in Europe range from nonexistent to low. A German Junior Professor may receive $€ 60,000$ $(\$ 73,200)$. French funding agencies have recently begun awarding start-up funds of $€ 60,000-140,000$ to select young investigators. However, these are highly competitive: in 2003 one of these programs funded only 87 of 1221 applicants. Not enough, says Franck Polleux, a developmental neuroscientist who after postdoctoral training in the US returned to France to start his own laboratory in an INSERM unit in Lyon, only to quit two years later for an assistant professorship at the University of North Carolina.

Certainly more money is always welcome, but another part of the problem is how available research funds are administered. The European Union provides some funds for neuroscience, through its Sixth Framework Programme (FP6) and individual fellowships. Pierre Magistretti of the University of Lausanne, Switzerland, and recent president of FENS, estimates that the EU contributes less than $10 \%$ of neuroscience funding in Europe. Funding basic research is not a priority; the official goal of FP6 is to "strengthen the scientific and technological bases of industry and encourage its international competitiveness."

Thus FP6 focuses on applied science, and its procedures are more common to industrial development than basic research. The European Commission issues calls for applications on clearly circumscribed projects deemed to be in the best interest of European society. The projects are defined in an extensive process of consultation, involving national program committees and scientific advisory boards. The Third Call, issued this June, includes projects on synaptic information processing, neuroimmune disorders, dyslexia and sleep. Because an overarching goal of FP6 is to foster cooperation across borders, applications may be submitted only by consortia including scientists from at least three European countries.

Successful consortia are rewarded not with the usual grant money, but with a legally binding contract. Erwin Neher, of the Max-PlanckInstitute for Biophysical Chemistry in Goettingen, Germany, compares the process to the procurement and bidding procedures for municipal building projects. The contracts spell out tasks and expected results, with detailed milestones. Researchers need to be careful negotiating and wording their contract, because they may in theory be held liable in case of non-delivery of results, says Neher.

Juan Lerma of the Instituto Cajal in Madrid, Spain, served as a reviewer during the First Call of FP6, and found the experience frustrating. There is not enough money to go around, he says, and excellent proposals fall by the wayside. Also, FP6, unlike previous Framework Programmes, focuses on large-scale collaborative projects that typically include 10 to 30 research teams, so a large proportion of the awarded money is spent for coordination, administrative and travel costs.

Jean-Philippe Deslys, a neuroscientist at the French Commissariat for Atomic Energy, believes that such Framework projects have merit. $\mathrm{He}$ is the coordinator of NeuroPrion, an FP6-funded "Network of Excellence" that aims to prevent future outbreaks of BSE-like diseases. It encompasses 52 research organizations. Over five years, NeuroPrion will receive a total of $€ 14.4$ million, which if evenly distributed would be about $€ 20,000$ per participant per year. The task of NeuroPrion therefore is not to directly fund research, but to coordinate efforts among consortium members, jump-start risky projects, and help groups apply for third-party funding. Is the effort worth it, despite the relatively small payouts? Yes, says Deslys, who is convinced that in complicated areas with far-reaching implications such as prion diseases, "research must be structured."

Not everyone agrees. Many European researchers deplore the inflexibility of the narrowly defined calls and contracts as completely at odds with scientific freedom. The earmarking of funds for specific goals limits competition, and the stringent requirement to form transnational consortia leads to wasteful, on-paper-only collaborations. Adriano Aguzzi, a prion researcher from the University of Zurich, Switzerland, remarks only half-jokingly that "Framework is good to have fun and make friends across borders, but does nothing for scientific excellence."

Even those scientists most critical of current EU programs support neuroscience funding on a European level in principle. The question is how to improve the system. Successful national funding programs in Europe and North America largely rely on a 'bottom-up' mechanism, where individual researchers propose projects, instead of responding to calls in a 'top-down' process. European scientists have long called for a European Research Council (ERC) that would peer review and fund individual proposals strictly according to scientific merit. In an encouraging move, the European Commission recently embraced this idea, and declared its aim to double overall EU funding for science and technology in the Seventh Framework Programme, scheduled to begin in 2006. The structure of the ERC and its relation to and independence from the Framework program still need to be worked out. The Commission is collecting input from interested parties about EU science policy at http://europa.eu.int/comm/research/future/index_en.html. We encourage European neuroscientists to participate in this process. Improved funding of their work should help reverse the brain drain and might even attract overseas scientists to European shores. 